\title{
Comparison of antibody level after SARS-CoV-2 infection in case of home treated and hospital treated patients
}

\author{
Chowdhury ${ }^{a}$, Mishu FA ${ }^{b}$, Alam MMc, Yasmin R $^{d}$, Rahman MM ${ }^{e}$, Mollah FH ${ }^{f}$
}

\begin{abstract}
Background:The severe acute respiratory syndrome coronavirus 2 (SARS-CoV-2) has spread throughout the world causing a serious health issue. After the swine flu pandemic (also known as H1N1) of 2009-10, WHO had declared Coronavirus disease 2019 (COVID-19) as a global pandemic. This pandemic caused huge losses to the entire world. Most of the patients with mild symptoms were treated at home but patients with difficulty in breathing and various complications were treated at the hospital. Naturally produced antibodies or vaccination can only offer protection. The objective was to compare the antibody status after SARS-CoV-2 infection in hometreated and hospital-treated patients.
\end{abstract}

Methods: This cross-sectional study was conducted in the Department of Biochemistry and Molecular Biology, BIRDEM General Hospital, from July, 2020 to June, 2021. A total of 77 patients (age 18 - 70 years) infected by SARS-CoV-2 were enrolled for this study. Among them, 37 were home treated and 40 were treated in hospital. The study subjects were non-vaccinated. For this study, serum IgG level was measured by the automated analyser. For statistical analysis, the Mann Whitney U test was done.

Results:The median value of serum IgG was significantly higher in hospital-treated patients than in hometreated patients $(p<0.001)$. Hospital treated patients with a history of comorbidity developed more amount of antibody in comparison to home treated patients.

Conclusion:Hospital treated patients develop higher antibodies in comparison to home treated patients.

Key words: SARS-CoV-2, antibody, comparison.

(BIRDEM Med J 2022; 12(1: 11-15)

Author information

a. Indira Chowdhury, Lecturer, Department of Biochemistry and Molecular Biology, Sheikh Hasina Medical College, Jamalpur, Bangladesh. Email: indirachy89@gmail.com

b. Farzana Akonjee Mishu, Associate Professor, Department of Biochemistry and Molecular Biology, BIRDEM General Hospital, Dhaka, Bangladesh.

c. Mohammad Masum Alam, Assistant Professor, Department of Biochemistry and Molecular Biology, BSMMU, Dhaka, Bangladesh.

d. Rubina Yasmin, UH\&FPO, Modhupur, Tangail, Bangladesh.

e. Mohammad Matiur Rahman, Professor, Department of Biochemistry and Molecular Biology, BSMMU, Dhaka, Bangladesh.

f. Forhadul Hoque Mollah, Professor, Department of Biochemistry and Molecular Biology, BSMMU, Dhaka, Bangladesh.

Address of correspondence: Indira Chowdhury, Lecturer, Department of Biochemistry and Molecular Biology, Sheikh Hasina Medical College, Jamalpur, Bangladesh. Email: indirachy89@gmail.com

Received:November 19, 2021

Revision received: December 2, 2021

Accepted: December 10, 2021

\section{INTRODUCTION}

The Coronavirus disease 2019 (COVID-19) caused by severe acute respiratory syndrome coronavirus 2 (SARS$\mathrm{CoV}-2$ ) is a pandemic experienced by the world. SARS$\mathrm{CoV}-2$ is a large, enveloped, positive-stranded RNA virus. ${ }^{1}$ It has four structural proteins: spike (S), envelope (E), membrane (M) and nucleocapsid (N) proteins. The receptor-binding domain (RBD) of the spike protein acts as an antigen for identifying immune reactions. ${ }^{2} \mathrm{~B}$ cells produce immunoglobulin as one of the essential components of the adaptive immune response. ${ }^{3}$ Immunoglobulin $\mathrm{G}$ is a major class of immunoglobulin that remains in the blood. It has long term immunity and immunological memory. ${ }^{4}$ The spike protein facilitates viral entry into host cells by binding to a host receptor through the RBD in the S1 subunit. Afterwards, viral and host membranes fuse through the S2 subunit. Antibodies binding to the spike (S) protein's RBD can 
neutralize SARS-CoV-2. ${ }^{2} \mathrm{~S} 1$ and $\mathrm{S} 2$ subunits of the viral spike protein act as antigen and anti-S1, anti-S2 IgG are produced within the body. ${ }^{5}$ A prospective study in Korea investigated antibody production in asymptomatic and mild COVID-19 patients. The study reported that neutralizing antibody production was significantly lower in asymptomatic to mild symptomatic patients than moderate to severe patients with pneumonia. ${ }^{6}$ Another prospective cohort study in the Netherlands reported that hospital admitted patients with respiratory insufficiency, hemodynamic instability and/or multiorgan failure showed strong immune response by producing $\operatorname{IgG}$ and $\operatorname{IgM}$ within 2-5 days after onset of symptoms. The antibody level was high after 3-4 weeks. But non-hospitalized home-treated patients developed an antibody with a significant lower titer. ${ }^{7}$ A hospitalbased case-control study reported IgG was detectable after one week and remained high for a long time. High disease activity and/or compromised immune response might cause this. ${ }^{8}$ A case-control study investigated that the concentration of $\mathrm{IgG}$ was lowest in early disease stages. After 21-25 days of infection, IgG was comparatively high. ${ }^{9}$ A cross-sectional study in India reported $\operatorname{IgG}$ appeared two weeks after infection and sustained high for a long time. ${ }^{10}$ The presence of antispike or anti-nucleocapsid IgG antibodies were associated with a substantially reduced risk of SARSCoV-2 reinfection in the following six months. ${ }^{11}$ Another study in Sweden reported that time to seroconversion was significantly shorter (median 11 vs. 22 days, p 0.04) in patients with severe symptoms compared to mild symptoms. Patients with severe SARS-CoV-2 infection both seroconvert earlier and develop higher concentrations of SARS-CoV-2-specific IgG. ${ }^{12}$ A retrospective cohort study comparing the immunologic status of SARS-CoV-2 infected patients with type 2 diabetic and non-diabetic individuals. The study revealed no significant difference between the two groups. ${ }^{13}$ Another study reported SARS-CoV-2 hypertensive patients' condition deteriorated more rapidly than the non-hypertensive group. ${ }^{14} \mathrm{~A}$ study in Abu Dhabi reported that a possible correlation remained between very high antibody levels and the severity of the disease. There might be an association between very high antibody titers and severity of the disease, the effects of other confounding factors like viral load, age, comorbidities, cell-mediated immune response. ${ }^{15}$
A recent study identified diseases severity was related to higher antibodies against SARS-CoV-2. The study agreed that advancing age and comorbidities had an obvious effect on IgG1 and IgG3 against SARS-CoV-2. There might be associations of antibody development with viral load. The immune response in patients differs with diverse clinical outcomes. So, antibody level varies from person to person. ${ }^{16}$ However, there were limited ideas about the duration of persistence of antibody after infection, IgG level in patients with comorbidities like hypertension, diabetes etc. So far, the literature review revealed scarce of relevant correlational study in Bangladesh. Considering the circumstances, the present study was undertaken to know the quantitative antibody status of home-treated and hospital-admitted patients.

\section{METHODS}

This cross-sectional study was conducted at the Department of Biochemistry and Molecular Biology, BIRDEM General Hospital, Shahbag, Dhaka from July, 2020 to June, 2021. A total of 77 study subjects, who had confirmed COVID-19 and recovered (37 hometreated patients were taken as group I and another 40 hospital-treated patients were taken as group II). The inclusion criteria for group I and II were RT-PCR positive for SARS-CoV-2 within last 3 to 6 monhts age 18 to 70 years. The exclusion criteria for this study were vaccinated patients against SARS-CoV-2 virus, pregnancy, lactation, chronic liver and renal disease, history of heart failure, any malignancy, any immunosuppressive disorders and radiation therapy. The research protocol was approved by the Institutional Review Board (IRB) of BIRDEM Academy, Shahbag, Dhaka. A structured questionnaire and data sheet were prepared for this research, which included all the variables of interest. With all aseptic precautions blood sample was collected. The serum was separated from individual sample and stored at $-56^{\circ} \mathrm{C}$. Estimation of serum IgG was performed at the Department of Biochemistry and Molecular Biology, BSMMU and assessed by Chemiluminescent Microparticle Immunoassay (CMIA) using Abbott Allinity i Autoanalyzer(USA).

Collected data were entered, checked and edited (to remove the outliers) with the help of the Statistical 
Package for Social Sciences (SPSS) software, version 26 and analysed. The data were expressed as frequency and percentage, mean \pm SD for normally distributed data or median (inter-quartile range) for data not normally distributed. The Mann-Whitney U test was done to compare IgG status between home and hospital treated post-COVID-19 patient groups. p value d"0.05 was considered statistically significant.

\section{RESULTS}

A total of 77 study subjects, who were infected 3 to 6 months ago, were enrolled for this study. The mean \pm SD age of home treated patients was $40.7 \pm 14.7$ and hospital treated patients was $49.6 \pm 10.9$ years. In comparison to the females, it was observed that males were more infected and needed hospital support (Figure 1).

Fever, cough, anosmia and respiratory distress were the most prominent symptoms among the patients who needed hospital support. On the other hand, fever, cough, anosmia, headache, vertigo were the notable symptoms observed in the home treated group (Table I).

Significantly $(\mathrm{p}<0.001)$ higher IgG was observed in hospital-treated patients compaired to home treatment

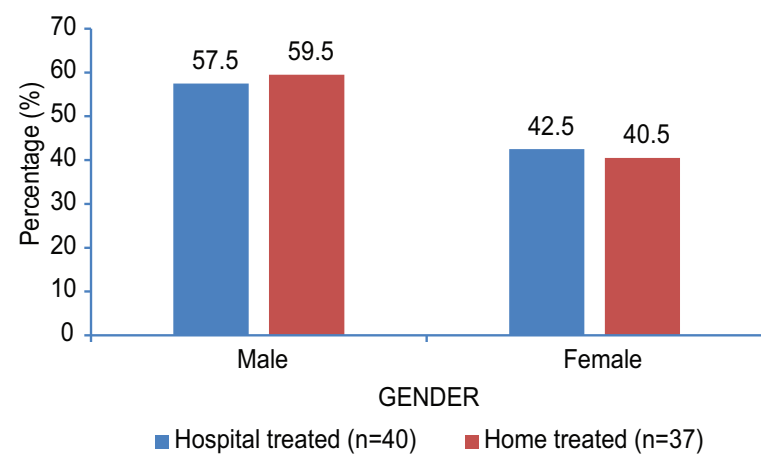

Figure 1 Gender distribution of the study subjects $(\mathrm{N}=77)$

patients. The median value of IgG with IQR was $316 \mathrm{AU} /$ $\mathrm{ml}(53.0-929.0)$ in home-treated patients, $3871.3 \mathrm{AU} / \mathrm{ml}$ (795.0-10,211.0) in hospital-treated patients (Table II).

Here hospital treated group had a more positive history of comorbidities than home treated group. Moreover, the hospital treated patients with history of comorbidity developed more antibodies than home treated patients (Table III).

Table I Distribution of the respondents according to their symptoms ( $\mathrm{N}=77)$

\begin{tabular}{lcc}
\hline Symptoms & $\begin{array}{c}\text { Home Treated } \\
(\mathrm{n}=37)\end{array}$ & $\begin{array}{c}\text { Hospital Treated } \\
(\mathrm{n}=40)\end{array}$ \\
\hline Fever, cough, anosmia, respiratory distress & $4(10.8 \%)$ & $27(67.5 \%)$ \\
Fever with cough & $13(35.1 \%)$ & $8(20.0 \%)$ \\
Fever, cough, anorexia, vertigo & $2(5.4 \%)$ & $4(10.0 \%)$ \\
Cough & $9(24.3 \%)$ & $0(0.0 \%)$ \\
Anosmia & $6(16.2 \%)$ & $0(0.0 \%)$ \\
Weakness, headache & $2(5.4 \%)$ & $1(2.5 \%)$ \\
Fever & $1(2.7 \%)$ & $0(0.0 \%)$ \\
\hline
\end{tabular}

Table II Distribution of the respondents according to $\operatorname{IgG}(\mathrm{AU} / \mathrm{ml})$ status $(\mathrm{N}=77)$

\begin{tabular}{lccc}
\hline & $\begin{array}{c}\text { Home Treated } \\
(\mathrm{n}=37)\end{array}$ & $\begin{array}{c}\text { Hospital Treated } \\
(\mathrm{n}=40)\end{array}$ & $\mathrm{p}$-value \\
\hline Median with range of IgG(AU/ml) & 316.1 & 3871.3 & \\
& $(53.0-929.0)$ & $(795.0-10211.0)$ & $<0.001$ \\
\hline
\end{tabular}

Data were expressed as median (Inter Quartile Range, IQR). 
Table III Distribution of IgG level with the history of co-morbidity ( $\mathrm{N}=77$ )

\begin{tabular}{lcccc}
\hline $\begin{array}{l}\text { Co } \\
\text { morbidity } \\
\text { of the } \\
\text { patients }\end{array}$ & $\begin{array}{c}\text { Home } \\
\text { Treated } \\
(\mathrm{n}=37)\end{array}$ & $\begin{array}{c}\text { IgG level } \\
\text { (Median) with } \\
\text { range of home } \\
\text { treated group } \\
\text { AU/ml }\end{array}$ & $\begin{array}{c}\text { Hospital } \\
\text { Treated } \\
(\mathrm{n}=40)\end{array}$ & $\begin{array}{c}\text { IgG level } \\
\text { (Median) with } \\
\text { range of } \\
\text { hospital treated } \\
\text { groupAU/ml }\end{array}$ \\
\hline HTN, DM & $4(10.8 \%)$ & 354.0 & $6(15.0 \%)$ & 2232.6 \\
DM & $1(2.7 \%)$ & 251.6 & $12(30.0 \%)$ & $(1303.5-4941.7)$ \\
HTN & $(53.0-462.0)$ & & 4193.0 \\
None & $3(16.2 \%)$ & $(157.6-720.9)$ & $10(25.0 \%)$ & $(1090.1-6654.0)$ \\
& $26(70.3 \%)$ & 336.8 & $12(30.0 \%)$ & 4877.5 \\
Total & $(56.0-896.0)$ & & $(1904.6-14,693.0)$ \\
\hline
\end{tabular}

\section{DISCUSSION}

In this cross-sectional study, SARS-CoV-2 infection and rate of hospitalization was more in males than females. This finding was consistent with a recent study in Chicago done by Gomez et al. ${ }^{17}$ The study mentioned that males had higher hospitalisation rates(19\% vs $13 \%)$. Another cross-sectional study in Italy done by Vahidy et al. also reported that males compared to females were $17.0 \%$ vs $14.6 \% .{ }^{18}$ Respiratory distress (67.5\%) was more predominant manifestation observed in hospital-treated patients. Home-treated patients presented mostly fever with cough, anosmia etc.In agreement with the study of Pritchard G M et al. mentioned, hospitalized SARS-CoV2 patients manifested fever (69\%), cough (68\%) and shortness of breath $(66 \%)$ mostly. ${ }^{19}$ In this study $\operatorname{IgG}$ was measured and compared between home and hospital treated groups. The median value of IgG was found significantly higher in hospital-treated patient group. These findings were in agreement with Liu et al. that reported a significant difference $(p<0.05)$ of $\operatorname{IgG}$ levels between mild and severe cases. This study observed that IgG level is lower in home treated SARSCoV-2 patients. ${ }^{20}$

This study observed that hospital treated SARS-CoV-2 patients had a previous history of comorbidities such as hypertension, diabetes mellitus and both diabetes and hypertension. A retrospective cohort studydone by Mejia et al. reported that most of the patients $(68.56 \%)$ had at least one comorbidity. This study in Peru mentioned more frequency of diabetes mellitus $(21.95 \%)$ and hypertension (21.68\%) were recorded among patients. $^{21}$

It was reported that hospital-treated patients with a history of comorbidity developed more antibodies than home-treated patients. A study by Jin et al. investigated about serum antibodies in hospitalized patients with comorbidities like hypertension in older age. IgG persisted at a high level up to 8 weeks $(130.6 \pm 25.0 \mathrm{AU} /$ $\mathrm{ml}) .22$

\section{Conclusion}

The antibody level of hospital-treated patients was significantly higher than that of home treated COVID19 patients.

Authors' contribution: IC: Conceptualization, collecting data, literature search and writing manuscript, review, editing and data analysis. FHM: Conceptualization, review, supervision. MMR, FAM, MMA and RY: Review and supervision.

Conflicts of interest: Nothing to declare.

Funding: Bangladesh Medical Research Council (BMRC). 


\section{REFERENCES}

1. Long QX, Deng HJ, Chen J, Hu J, Liu BZ, Liao P, et al. Antibody responses to SARS-CoV-2 in COVID-19 patients: the perspective application of serological tests in clinical practice. MedRxiv 2020 Jan; 1-20.

2. Shirin T, Bhuiyan TR, Charles RC, Amin S, Bhuiyan I, Kawser Z, et al. Antibody responses after COVID-19 infection in patients who are mildly symptomatic or asymptomatic in Bangladesh. International Journal of Infectious Diseases 2020; 101(12): 220-5.

3. Fereidan-Esfahani M, Nayfeh T, Warrington A, Howe CL, Rodriguez M. IgM natural autoantibodies in physiology and the treatment of disease. Human Monoclonal Antibodies 2019; 13(7):53-81.

4. Ma H, Zeng W, He H, Zhao D, Yang Y, Jiang D, et al. COVID-19 diagnosis and study of serum SARS-CoV-2 specific $\operatorname{IgA}, \operatorname{IgM}$ and $\operatorname{IgG}$ by chemiluminescence immunoanalysis. MedRxiv 2020 Jan; 30(4): 1-18.

5. Zeng F, Hon CC, Yip CW, Law KM, Yeung YS, Chan KH, et al. Quantitative comparison of the efficiency of antibodies against S1 and S2 subunit of SARS coronavirus spike protein in virus neutralization and blocking of receptor binding: implications for the functional roles of S2 subunit. FEBS Letters 2006; 580(24): 5612-20.

6. Ko JH, Joo EJ, Park SJ, Baek JY, Kim WD, Jee J, et al. Neutralising antibody production in asymptomatic and mild COVID-19 patients, in comparison with pneumonic COVID-19 patients. Journal of Clinical Medicine 2020 Jul;9(7):2268-9.

7. Rijkers G, Murk JL, Wintermans B, Van Looy B, Van den Berge M, Veenemans J, et al. Differences in antibody kinetics and functionality between severe and mild severe acute respiratory syndrome coronavirus 2 infections. The Journal of Infectious Diseases 2020; 222(8): 1265-9.

8. Hou H, Wang T, Zhang B, Luo Y, Mao L, Wang F, et al. Detection of $\operatorname{IgM}$ and $\operatorname{IgG}$ antibodies in patients with Coronavirus disease 2019. Clinical \& Translational Immunology 2020; 9(5): e1136.

9. Ma H, Zeng W, He H, Zhao D, Yang Y, Jiang D, et al. COVID-19 diagnosis and study of serum SARS-CoV-2 specific IgA, IgM and IgG by chemiluminescence immunoanalysis. MedRxiv 2020 Jan; 8(5): 1-9.

10. Khan SM, Qurieshi MA, Haq I, Majid S, Bhat AA, Nabi S, et al. Seroprevalence of SARS-CoV-2 specific IgG antibodies in District Srinagar, northern India-a crosssectional study. PLOS ONE 2020 Nov;15(11):e0239303.

11. Lumley SF, O'Donnell D, Stoesser NE, Matthews PC, Howarth A, Hatch SB, et al. Antibody status and incidence of SARS-CoV-2 infection in health care workers. New England Journal of Medicine 2021 Feb;384(6):533-40.

12. Marklund E, Leach S, Axelsson H, Nyström K, Norder H, Bemark M, et al. Serum-IgG responses to SARS-CoV-2 after mild and severe COVID-19 infection and analysis of IgG non-responders. PLOS ONE 2020; 15(10): e0241104.

13. Zhao R, Sun Y, Zhang Y, Wang W, Wang S, Wang C, et al. Distinguishable immunologic characteristics of COVID19 patients with comorbid type 2 diabetes compared with nondiabetic individuals. Mediators of Inflammation 2020 Oct; 10(7): 1-8.

14. Emami A, Javanmardi F, Akbari A, Kojuri J, Bakhtiari H, Rezaei T, et al. Survival rate in hypertensive patients with COVID-19. Clinical and Experimental Hypertension 2021 Jan;43(1):77-80.

15. Alzaabi AH, Ahmed LA, Rabooy AE, Zaabi AA, Alkaabi $\mathrm{M}$, AlMahmoud F, et al. Longitudinal changes in IgG levels among COVID-19 recovered patients: A prospective cohort study. PLOS ONE 2021 Jun;16(6):e0251159.

16. Luo H, Jia T, Chen J, Zeng S, Qiu Z, Wu S, et al. The characterization of disease severity associated IgG subclasses response in COVID-19 patients. Frontiers in Immunology 2021;12(4): 1-7.

17. Gomez JM, Du-Fay-de-Lavallaz JM, Fugar S, Sarau A, Simmons JA, Clark B, et al. Sex Differences in COVID19 Hospitalisation and Mortality. Journal of Women's Health 2021 May;30(5):646-53.

18. Vahidy FS, Pan AP, Ahnstedt H, Munshi Y, Choi HA, Tiruneh Y, et al. Sex differences in susceptibility, severity, and outcomes of coronavirus disease 2019: Cross-sectional analysis from a diverse US metropolitan area. PLOS ONE $2021 \mathrm{Jan} ; 16(1): \mathrm{e} 0245556$.

19. Pritchard MG. COVID-19 symptoms at hospital admission vary with age and sex: ISARIC multinational study. Medrxiv 2020 Jan; 1(1): 1-5.

20. Liu X, Wang J, Xu X, Liao G, Chen Y, Hu CH. Patterns of IgG and IgM antibody response in COVID-19 patients. Emerging Microbes \& Infections 2020; 9(1): 1269-74.

21. Mejía F, Medina C, Cornejo E, Morello E, Vásquez S, Alave J, et al. Oxygen saturation as a predictor of mortality in hospitalized adult patients with COVID-19 in a public hospital in Lima, Peru. PLOS ONE 2020; 15(12): e0244171.

22. Jin JM, Bai P, He W, Wu F, Liu XF, Han DM, et al. Gender differences in patients with COVID-19: focus on severity and mortality. Frontiers in Public Health 2020 Apr;8(29):152. 